\title{
ESTUDO FACIOLÓGICO DOS AFLORAMENTOS DE BOM DESPACHO (BA): RITMITOS E SEDIMENTOS DE ÁGUAS PROFUNDAS ASSOCIADOS
}

\author{
PEDRO VICTOR ZALÁN*, ANTÔNIO JOSÉ PINHEIRO RIVAS*, GILBERTO GERMANY HERTER*, JOSÉ \\ CARLOS RABELO FROES*, MARIA DA GLÓRIA DA SILVA* e ADROALDO MENDES CAMÕES*
}

\begin{abstract}
Five sedimentary facies were distinguished in the two outcrops studied and were in. terpreted in the following manner: one facies represents the deposition at the bottom of the basin (black shale facies); three facies represent a turbiditic lobe (facies of sandy rhytmites, facies of shaly rhytmites, and facies of lenticular sandstones); and the last is a slumping facies representing a slope deposition (green shale facies). After this; the work proceeded with the integration of the data obtained with the litostratigraphy of the Recôncavo Basin.
\end{abstract}

INTRODUÇÃO Este trabalho teve por objetivo o estudo faciológico de dois afloramentos situados na localidade de Bom Despacho, llha de Itaparica, Baía de Todos os Santos, Bahia. Os afloramentos situam-se em praias localizadas nas vizinhanças do terminal do ferryboat que liga a ilha a Salvador, estando um a sudeste (entre o terminal e a localidade de Gameleira) e o outro a nordeste (entre o terminal e a localidade de Porto Santo) (Fig. 1). A lavagem constante efetuada pelas marés originou excelentes exposiçð̃es. Uma delas, a situada a sudeste, foi objeto de descrição por Ghignone (1978). Os afloramentos consistem em rochas sedimentares pertencentes à Bacia do Recôncavo, desenvolvida durante o Jurássico Superior e Cretáceo Inferior.

O estudo faciológico de rochas sedimentares permite a caracterização e a separação de várias fácies. Delas podemos inferir os processos atuantes durante o transporte, a deposição, o período pós-deposicional (quando os sedimentos ainda estavam inconsolidados) e a diagênese dos sedimentos.

O trabalho constou do reconhecimento, individualização, descrição detalhada e levantamento estratigráfico das diversas fácies existentes nos afloramentos. Uma vez entendidas as fácies determinou-se o sistema deposicional responsável pela origem das mesmas. Consideraçðes acerca de paleocorrentes, localização e proximidade das áreas-fonte foram também tecidas ao final deste estudo.

O embasamento teórico utilizado na realização desta pesquisa encontra-se amplamente divulgado na bibliografia geológica. $O$ conceito de fácies sedimentares, seu reconhecimento e interpretação podem ser encontrados em Medeiros et alii (1971). Os mecanismos de transporte de sedimentos para águas profundas foram estudados por Middleton e Hampton (1976). Mais particularmente, as correntes de turbidez, os turbiditos e as fácies turbidíticas foram objetos de inúmeros trabalhos: Bouma (1962), Walker (1978), Apoluceno e Zalán (1979), etc. A geologia regional da Bacia do Recôncavo foi estudada por Viana (1971), Ghignone (1972) e Netto (1978).

\section{GEOLOGIA LOCAL}

\section{a) RECONHECIMENTO DAS FÁCIES E SUAS DESCRIÇÕES}

Cinco fácies diferentes foram reconhecidas nos dois afloramentos estudados. $O$ reconhecimento e a individualização das fáceis foram baseados na litologia, textura, estruturas sedimentares, geometria e paleocorrentes apresentadas por cada uma delas. Cada fácies foi denominada levando-se em conta a litologia e/ou estrutura mais marcante. A distribuição das cinco fácies pelos afloramentos é a seguinte:

i) Afloramento a sudeste

1) Fácies de ritmitos arenosos

2) Fácies de ritmitos argilosos

3) Fácies de arenitos lenticulares

ii) Afloramento a noroeste

4) Fácies de folhelhos verdes

5) Fácies de folhelhos pretos

Cada fácies foi estudada detalhadamente em lâminas petrográficas, descriçð̃es macroscópicas, levantamento das estruturas sedimentares, geometria dos corpos, medição de paleocorrentes e tipos de contatos. Procedeu-se também a um levantamento estrutural/estratigráfico das seçðes com o intuito de se obter as relaçðes espaciais entre as fácies. Os dados obtidos foram analisados em um subitem separado, visto que fornecem resultados interessantes.

Apresentamos a seguir a descrição detalhada de cada uma das cinco fácies.

\section{1) FACIES DE RITMITOS ARENOSOS}

Litologia Caracteriza-se pela alternância notável das camadas arenosas e argilosas, predominando as primeiras na proporção aproximada de $4 / 3$ (Foto 1). Os arenitos possuem coloraçoes claras (branco, amarelo, cinza), granulometria variável, predominando a faixa média/grosseira, por vezes conglomeráticos e com mui- 


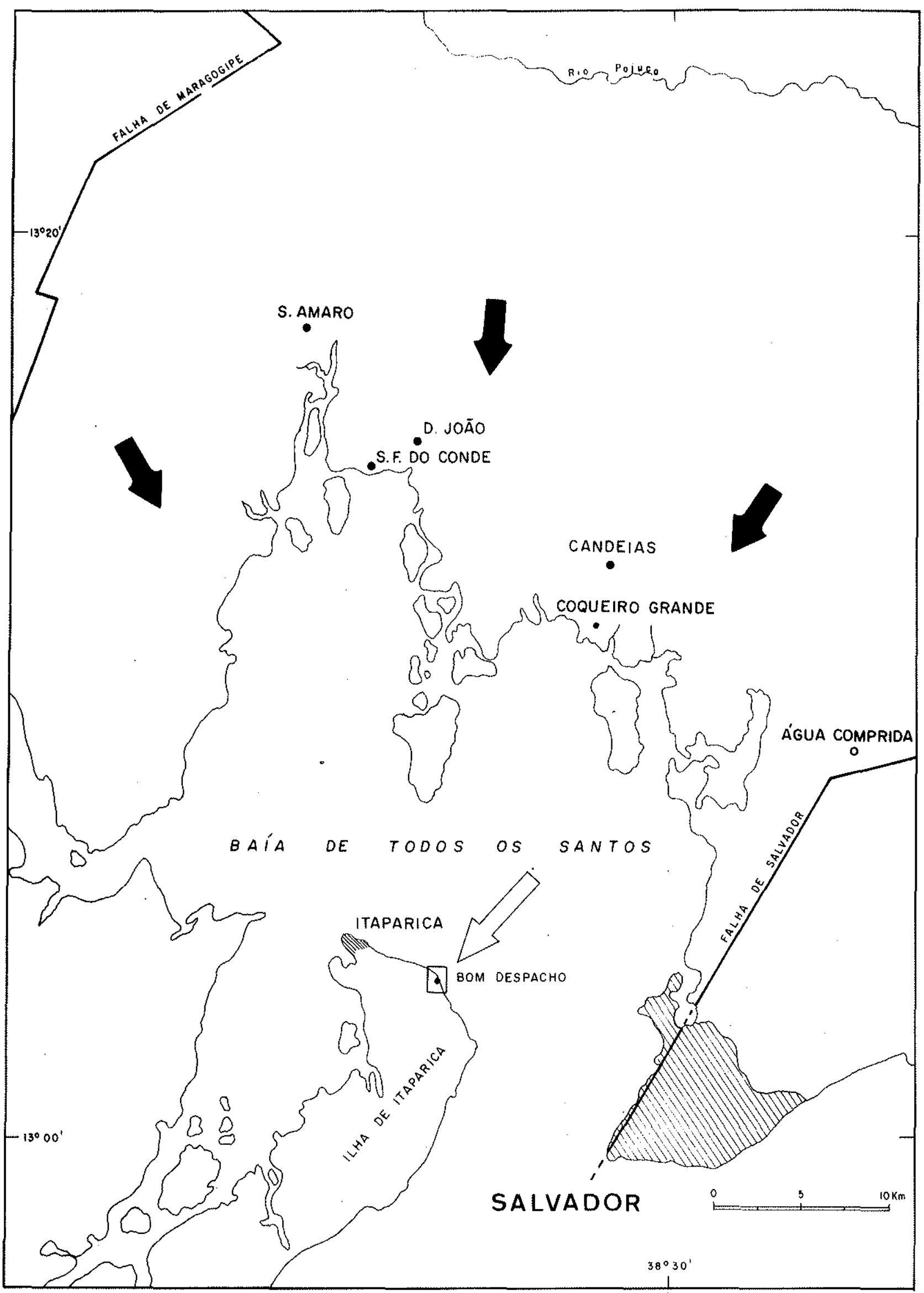

Figura 1 - Mapa de localização da área estudada e de direçōes de paleocorrentes (setas pretas) 
tas estruturas sedimentares (vide adiante). Microscopicamente, caracterizam-se por apresentar textura homogênea, empacotamento normal, seleção moderada e mediana granulométrica areia média. Constituem-se granulometricamente de grãos fraçåo areia (95\%), silte $(5 \%)$ e por vezes grãos cascalho (nunca superior a $5 \%$ ). $\mathrm{O}$ arcabouço mineralógico, em média, é formado por: quartzo comum $(85 \%)$, feldspato $(10 \%$, com predominância de K-feldspto sobre plagioclásio), fragmentos de rocha $(5 \%$, sílex e metamórficas quartzo feldspáticas). A matriz ocorre em porcentagens sempre muito inferiores a $5 \%$ e consiste em grãos tamanho silte de quartzo, feldspato e opacos. $O$ cimento perfaz cerca de $10 \%$ em volume da rocha e consiste em calcita espática. Observa-se frequientemente a presença de intraclastos de uma rocha carbonática oolítica, fragmentos de ostracóides e grãos subédricos de pirita. Considerando-se a classificação de Folk, esses arenitos têm em média uma composição subarcósica.

Os folhelhos são de dois tipos: o primeiro, muito mais abundante, é cinza-claro, raramente esverdeado, siltoso e frequientemente gradacional com o topo dos arenitos. $O$ segundo, muito mais raro, ocorre em camadas milimétricas e centimétricas em meio aos folhelhos anteriores. É preto betuminoso e extremamente físsil. Além desses, foi encontrada uma camada de diamictito cinza-claro/esverdeado, com seixos e grânulos de quartzo, folhelhos, feldspatos caulinizados, carvões e vegetais fósseis. Possui uma espessura de cerca de $30 \mathrm{~cm}$ intercalada em meio a arenitos com numerosos diques de areia e passando gradacionalmente a um delgado conglomerado no topo. Dolomitos escuros e argilosos ocorrem como concreçð̃es (septárias) e megaconcreçðes (métricas).

\section{Disposição geométrica/estratigráfica/estrutural A} caracterização mais marcante desta fácies é a intercalação monótona de arenitos e folhelhos, emprestando à fácies um caráter rítmico, razão pela qual assim foi denominada. Estruturalmente, ela é monótona, com uma estratificação bem desenvolvida, pouco perturbada por falhamentos normais e com um suave mergulho para nordeste (Foto 1). Estratigraficamente, ela encontra-se situada em meio a uma fácies de ritmitos extremamente

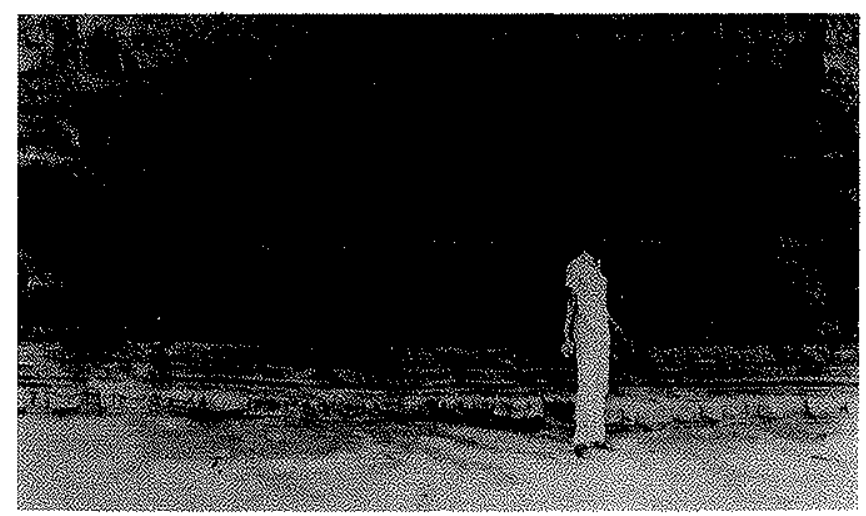

Foto 1 - Contato entre as fácies ritmito argiloso inferior e ritmitos arenosos semelhantes a estes só que com predomínio de folhelhos (fácies de ritmitos argilosos). O contato com essa fácies, tanto na base como no topo, é gradacional.

Geometricamente, os arenitos apresentam-se em camadas com espessuras decimétricas e extensões de dezenas de metros. Localmente, essas camadas vão-se afinando gradualmente até sumir. Um fenômeno muito comum é o amalgamamento de duas ou três camadas arenosas formando uma mais espessa. $O$ diamictito possui geometria idêntica, passando lateralmente para folhelhos siltosos.

Estruturas sedimentares Os arenitos desta fácies são muito ricos em estruturas sedimentares, uma lista das quais apresentamos a seguir: laminaçăo paralela (regime de fluxo superior), estratificação cruzada, marcas onduladas, laminaçðes convolutas, laminação paralela (regime de fluxo inferior), estruturas de escape de fluidos (pilares e outras), marcas de solas (estruturas de carga, estrias e turboglifos), pseudonódulos de arenitos (devido ao "afundamento" de bolsð̌es de areia em meio à argila), piled ripples, aleitamento gradacional (muito raro), diques de areia (contorcidos ou não), estruturas de escorregamento (raras, Foto 6) e septárias (dolomitos).

Diversas medidas de paleocorrentes foram tomadas utilizando-se algumas dessas estruturas (estratificaçðes cruzadas, marcas de sola). Os resultados serão analisados no subitem "medição de paleocorrentes".

Processos sedimentares Uma característica diagnóstica dos processos sedimentares atuantes na deposição dos arenitos é a superposição diversas vezes observada das seguintes estruturas: laminação paralela (regime de fluxo superior), laminaçðes cruzadas, onduladas e/ou convolutas, laminação paralela (regime de fluxo inferior) de arenitos muito finos e siltitos. Em dois locais esta sequêenciă é precedida por um nível conglomerático apresentando aleitamento gradacional normal. Toda essa sequiência é acompanhada por um decréscimo na granulometria, da base para o topo da camada. Tal seqüência de estruturas sedimentares caracteriza a seqủência de Bouma e identifica os agentes transportador e deposicional desses sedimentos: correntes de turbidez. Todas as outras estruturas confirmam tal interpretação visto que são freqüentemente associadas a turbiditos.

Assim sendo, os arenitos foram depositados principalmente por suspensão (há sempre uma componente de tração), nos regimes de fluxo superior (aleitamento gradacional e laminação paralela) e inferior (laminaçðes cruzadas, onduladas, convolutas e paralela de siltitos e areias finas). Um único corpo apresenta a seqüência de Bouma completa $\left(T_{a-e}\right)$, os outros a têm quase completa $\left(T_{b}-e\right)$ enquanto corpos amalgamados geralmente estão incompletos $\left(T_{a}, T_{a}-b, T_{a}-c\right)$ devido à erosão pelas corridas sobrepostas. A predominância é de arenitos com sequiência $T_{b-e}$, seguidos de arenitos $T_{c-e}$. Os folhelhos cinzentos representam a parte fina trazida pelas correntes de turbidez enquanto os folhelhos pretos provavelmente sejam oriundos da sedimentação normal da bacia, nas fases interturbidíticas. A espessura milimétrica desses últimos indica uma grande atividade de correntes de turbidez nessa época e nesse local. 


\section{2) FACIES DE RITMITOS ARGILOSOS}

Trata-se da mesma fácies anterior só que com um predomínio de folhelhos. As litologias (tanto em composição quanto em textura), suas geometrias, a disposição estrutural, as estruturas sedimentares, as paleocorrentes e os processos atuantes são rigorosamente os mesmos das fácies de ritmitos arenosos. Os contatos entre elas são gradacionais e estabelecidos pelos autores mais ou menos arbitrariamente, em função da predominância de folhelhos ou arenitos.

\section{3) FACIES DE ARENITOS LENTICULARES}

Litologia Caracteriza-se pela presença de um espesso corpo de arenito (no máximo $1,50 \mathrm{~m}$ ) de forma lenticular em meio a ritmitos argilosos semelhantes aos da fácies anterior (Foto 2). $\mathrm{O}$ arenito possui composição e textura parecidas com as dos arenitos das fácies de ritmitos. Camadas milimétricas de folhelhos ocorrem em seu interior.

\section{Disposição geométrica/estratigráfica/estrutural A característica mais marcante desta fácies é a lenticulari- dade do corpo de arenito observável em apenas uma ex- tremidade desta camada. A outra extremidade situa-se em uma parte do afloramento semidestruída pela erosão atual. Entretanto, na maré baixa, pode-se projetar este corpo em direção à praia e lá, em meio às camadas aflo- rantes, torna-se possível distinguir-se a base côncava pa- ra baixo deste arenito, quase que totalmente erodido. Abaixo desta lente ocorre uma outra camada mais del- gada de arenito, com uma geometria também semelhan- te a uma lente, mas não tão evidente quanto a anterior. \\ Estratigraficamente, esta fácies situa-se na parte mais basal do afloramento em meio à fácies de ritmitos argilosos. Estruturalmente, esta lente acompanha a es- tratificação dos ritmitos e parece estar encaixada e alon- gada segundo uma direção nordeste-sudoeste.}

Estruturas sedimentares Este arenito é semelhante aos arenitos da fácies de ritmitos, inclusive no tocante às estruturas sedimentares. Observam-se: laminação paralela (do regime de fluxo superior), laminaçóes onduladas, cruzadas e convolutas, laminação em feståo e laminação paralela (do regime de fluxo inferior).
Algumas direçðes de paleocorrentes foram tomadas obtendo-se um resultado compatível com as paleocorrentes medidas nas fácies de ritmitos ( $\mathrm{S} 40 \mathrm{~W}$, vide " $m e$ dição de paleocorrentes").

Processos sedimentares Devido à grande semelhança com as fácies anteriores, supðe-se que os processos de transporte e deposiçăo atuantes tenham sido os mesmos, ou seja, correntes de turbidez. Entretanto, em vez de as corridas espraiarem-se em forma de extensas camadas, parece-nos que aqui elas foram confinadas a uma região de geometria lenticular (canal ?).

A camada é composta pelo amalgamamento de diversos arenitos turbidíticos. Utilizando-se a sequência de Bouma e as delgadas camadas de folhelhos existentes, pode-se observar a superposição de até três corridas distintas.

\section{4) FACIES DE FOLHELHOS VERDES}

Litologia Caracteriza-se pela presença, em quantidades quase iguais, de pelitos de coloração verde, cinzaesverdeado e cinza, e arenitos de coloração claras (branco, amarelo, cinza) de granulometria média a grosseira, freqüentemente conglomeráticos, mal selecionados e portadores de abundantes seixos centimétricos do folhelho anteriormente descrito. É de se ressaltar o fato de esses arenitos serem muito semelhantes aos arenitos das fácies de ritmitos do outro afloramento, caracterizados em maior detalhe na descrição dessas fácies.

Subordinadamente, ocorrem dolomitos cinza-escuros ou pretos finos e duros (vide descrição detalhada na fácies seguinte).

Disposição geométrica/estratigráfica/estrutural A característica mais marcante desta fácies são os intensos e generalizados fenômenos de escorregamentos que provocaram o aparecimento de inúmeras dobras de caráter complexo, de grandes e pequenas amplitudes (Foto 3), o isolamento de bolsões de areia em meio ao folhelho (pseudonódulos), a deformação de estruturas internas e o deslocamento e o rompimento de camadas de arenitos em diversos pedaços espalhados em meio ao folhelho.

Com o intuito de melhor exemplificarmos a intensidade desses fenômenos de escorregamento, descreveremos uma camada de arenito situada no extremo noroes-

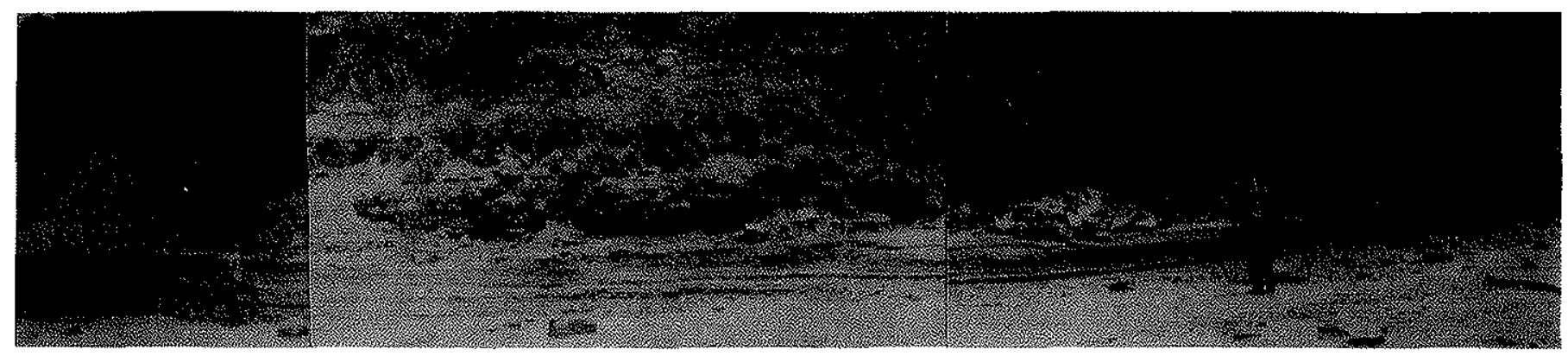

Foto 2 - Lente de arenito (fácies de arenitos lenticulares) 


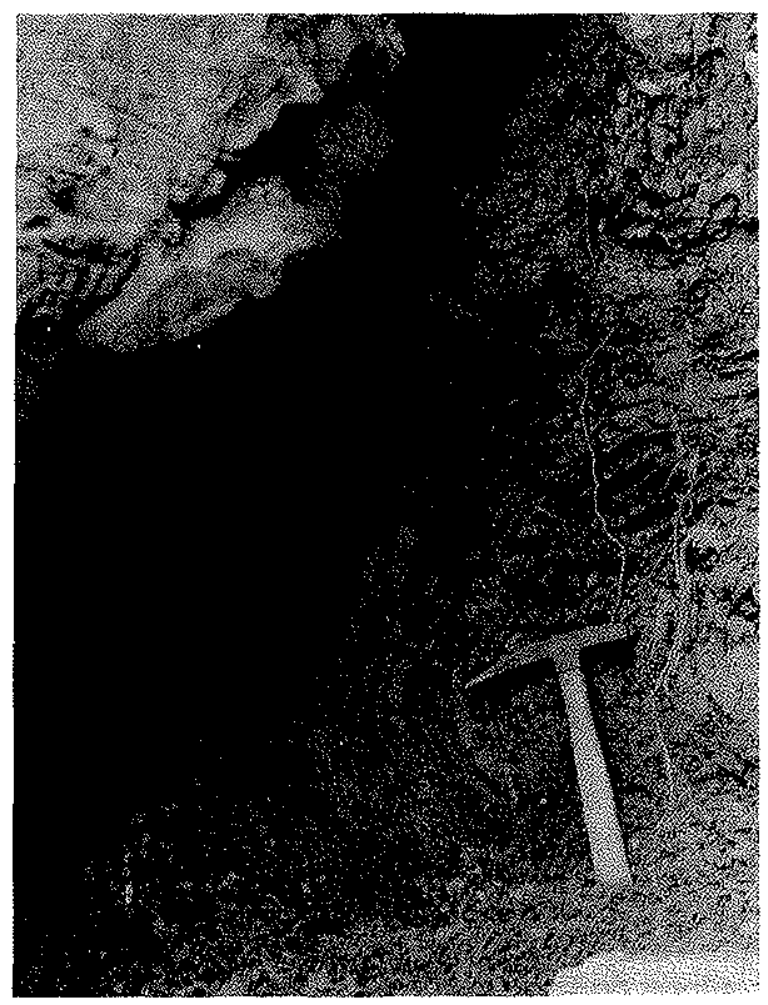

Foto 3 - Dobra de escorregamento na fácies de folhelhos verdes

te do afloramento. Trata-se de um turbidito com espessura de cerca de $1 \mathrm{~m}$, apresentando uma sequiência de Bouma muito bem desenvolvida $\left(T_{b-e}\right)$, permitindo sua fácil correlação entre vários pontos do afloramento. Em um círculo de raio igual a $10 \mathrm{~m}$, pudemos observar esta camada em três posiçóes completamente diferentes: a) em sua posição normal e quase horizontal; $b$ ) um pedaço dela encravado no folhelho e em posição vertical; e c) um outro pedaço dela em posição completamente invertida, com o intervalo $b$ no topo e o $d / e$ na base (Foto 4).

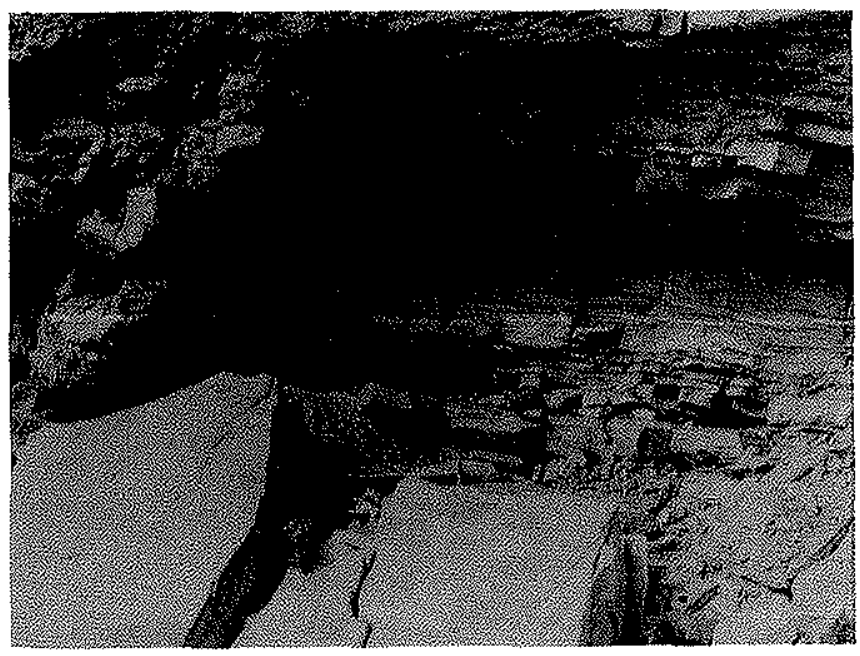

Foto 4 - Vista parcial da camada fragmentada: uma parte dobrada e outra revirada. A seta indica o topo (fácies de folhethos verdes)
A medição da direção dos eixos de algumas dobras assimétricas nos fornece a direção e o sentido dos escorregamentos perpendicular a esses eixos. Os escorregamentos apresentam notável uniformidade para $S 40^{\circ} \mathrm{W}$.

Estratigraficamente, esta fácies ocorre em dois níveis intercalados com a fácies de folhelhos pretos. Estruturalmente, não se pode falar em mergulho das camadas já que nesse amontoado de folhelhos e arenitos rompidos e contorcidos as direçðes e os ângulos de mergulho são os mais variados possíveis.

A geometria dos corpos arenosos não pode ser muito bem definida. Muito embora a maioria dos corpos deva ter tido um formato original de camadas, chama-se a atenção para um espesso corpo de areia ocorrente no extremo sudeste do afloramento. Trata-se de um arenito grosseiro, com muitos seixos de folhelhos uniformemente distribuídos e poucas estruturas (laminação paralela), possuindo uma geometria alongada restrita à feição de um canal. Poderia representar um canal preenchido por areias residuais do by-pass nas quais o fluxo de grãos tenderia a homogeneizá-las. Os dolomitos ocorrem em concreções e em camadas centimétricas.

Estruturas sedimentares As estruturas sedimentares observadas nos arenitos desta fácies foram: Iaminação paralela (intervalo $b$ de Bouma), raras laminações cruzadas, ondulada e convoluta (intervalo $c$ de Bouma), raríssimas laminaçóes paralelas (do regime de fluxo inferior, intervalo $d / e$ ) e freqüentes marcas de carga. Diques de areia são comuns assim como septárias.

Não foram tomadas medidas de sentidos de correntes devido ao fato de as camadas estarem altamente perturbadas pelos escorregamentos.

Processos sedimentares Os processos sedimentares atuantes na deposição desta fácies foram principalmente correntes de turbidez e talvez fluxo de grãos (nas areias canalizadas), em regimes de fluxo superior e inferior. Os arenitos turbidíticos apresentam predominantemente o intervalo $b$ de Bouma $\mathrm{e}$, às vezes, o intervalo $c$. Apenas uma camada de arenito apresentou uma seqüência mais completa $\left(T_{b-e}\right)$, estando além disso amalgamada com outras corridas. Os folhelhos verdes podem representar a parte fina das correntes de turbidez ou então a sedimentação normal do talude. Presume-se que estes representem uma fácies de talude devido aos intensos fenômenos de escorregamento tão comuns nessas regiôes e pela intercalação com fácies de fundo de bacia (vide fácies a seguir).

\section{5) FACIES DE FOLHELHOS PRETOS}

Litologia Caracteriza-se pela ampla predominância de folhelhos pretos, betuminosos, freqüentemente carbonosos (vegetais fósseis). Subordinadamente, ocorrem outras litologias, tais como: arenitos cinza-escuros, homogêneos, moderadamente selecionados, empacotamento fechado e com mediana granulométrica areia média. Granulometricamente, consistem em 95\% de grãos fração areia e $5 \%$ de fração silte. $O$ arcabouço mineralógico é formado por cerca de $65 \%$ de quartzo, em geral ondulante e apresentando às vezes inclusóes aciculares de rutilo, $15 \%$ de feldspatos (plagioclásio $>\mathrm{K}$ - 
feldspato), alguns já quase totalmente alterados (vacuolizados e caulinizados), $20 \%$ de fragmentos de rochas (sílex, calcário, metamórfica quartzo-feldspática e uma rocha rica em clorita e plagioclásio). A matriz ocorre em porcentagens nunca superiores a $5 \%$ e consiste em finas palhetas de clorita. Cimento (5\% em volume) ocorre sob duas formas: $a$ ) intersticial carbonático e $b$ ) silicoso (anéis sintaxiais em torno dos grãos de quartzo). A presença desse crescimento secundário de quartzo, associada à predominância de contatos do tipo côncavoconvexo, é evidência de que a rocha sofreu pressurewelding. Ostracóides também estão presentes. Segundo a classificação de Folk, esses arenitos são do tipo litoarenito feldspático; siltitos/argilitos castanhos e cinza-escuros, maciços e duros; e dolomitos que microscopicamente podem ser denominados microdoloespátitos, com impurezas de silte em torno de $10 \%$. É composto por um mosaico muito fino de romboedros de dolomita, onde flutuam grãos finos corroídos de quartzo, feldspato, opacos e palhetas de biotita. Os opacos estão liberando óxido de ferro, o que imprime à rocha uma tonalidade amarronzada. Segundo Cícero Pereira (comunicação oral), essas rochas seriam o produto da dolomitização de lamas carbonáticas (micritas). Observam-se ainda raras camadas de arenitos mais claros semelhantes aos da fácies anterior.

Disposição geométrica/estratigráfica/estrutural Esta fácies ocorre intercalada com a fácies anterior, conforme será discutido mais adiante no subitem "Estratigrafia". Estruturalmente, a fácies é monótona. A estratificação das camadas é bem desenvolvida e pouco perturbada por falhamentos normais, com um suave mergutho para nordeste.

Geometricamente, os arenitos apresentam-se em camadas pouco espessas (decimétricas/centimétricas) e extensas (dezenas de metros), isoladas ou raramente amalgamadas com outras lateralmente ou em bolsðes (Foto 5). Os siltitos/argilitos ocorrem em camadas centimétricas. Os dolomitos ocorrem como concreçð̃es, nódulos

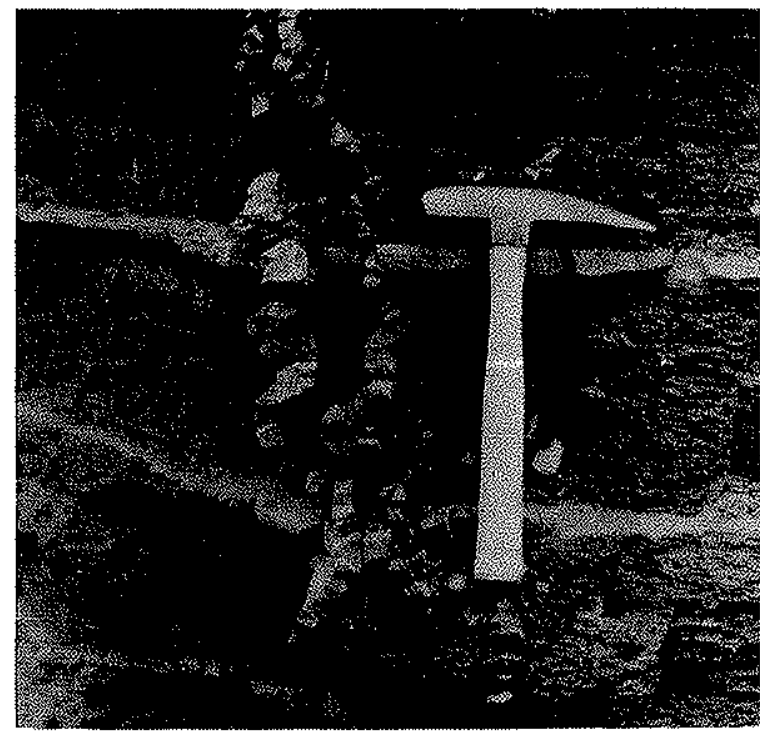

Foto 5 - Diques de areias contorcidos na fácies de folhelhos pretos ou como camadas centimétricas extensas. Todas essas litologias acham-se inclusas em espesso pacote de folhelhos pretos.

Estruturas sedimentares As estruturas sedimentares observadas nas litologias desta fácies foram: laminação paralela por tração (regime de fluxo superior) dada pela alternância de leitos arenosos de granulometrias diferentes, laminação paralela por suspensão (regime de fluxo superior) dada pela alternância de leitos siltosos e argilosos, laminação por suspensão (regime de fluxo superior) em arenitos laminados (intervalo a de Bouma), laminação cruzada de baixo ângulo, marcas de sola (estrias, flutes, chevron e cristas, e valas longitudinais), numerosos diques de areia com espessuras centimétricas e decimétricas, por vezes pouco contorcidos (Foto 5) e bolsóes (pseudonódulos) de areias, isolados da camada original, formados pelo afundamento de marcas onduladas empilhadas (piled load casted ripples) em meio aos folhelhos pretos (Foto 6).

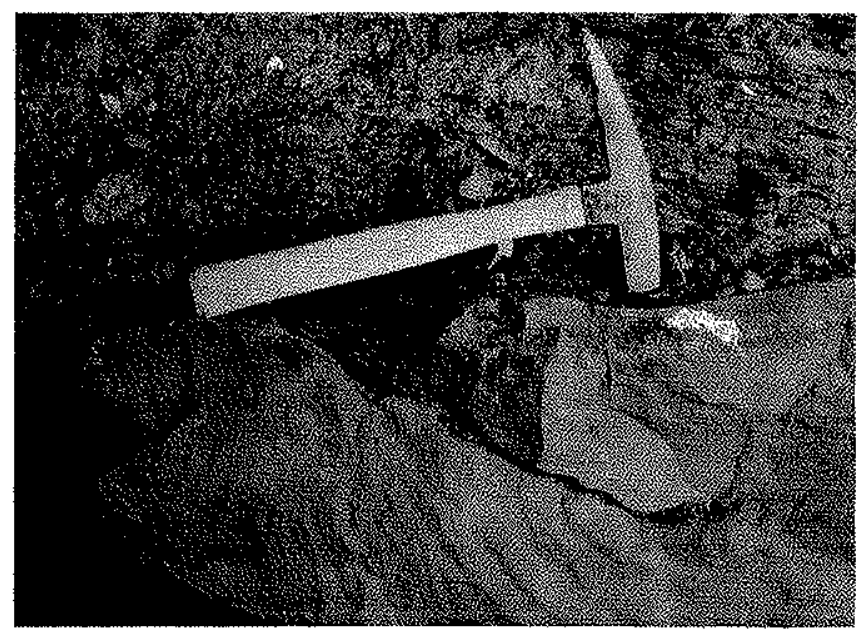

Foto 6 - Piled load casted ripples na fácies de folhelhos pretos

Algumas estruturas de marcas de sola foram utilizadas para medição de paleocorrentes (vide subitem "Medição de paleocorrentes"').

Processos sedimentares Os processos sedimentares atuantes na deposição desses arenitos e siltitos/argilitos foram correntes de suspensão, provavelmente correntes de turbidez.

Os arenitos apresentam, na maioria das vezes, o intervalo $b$ de Bouma e, raramente, o intervalo $c$ muito mal desenvolvido (laminações cruzadas de baixo ângulo). Os siltitos/argilitos poderiam representar turbiditos mais distais (intervalos $d / e$ ) enquanto faixas mais claras nos folhelhos seriam os resquícios de partes mais distais de pulsos turbidíticos. Entretanto há uma certa componente de tração associada a eles. Os sedimentos eram provavelmente altamente fluidizados devido à relativa ausência de estruturas nos arenitos e à grande quantidade de diques de areias.

Os folhelhos betuminosos representam a deposição normal de fundo de bacia (suspensão) em ambiente redutor. 


\section{b) ESTRATIGRAFIA}

Como já foi dito, neste trabalho foram estudados dois afloramentos situados numa linha sudeste-noroeste, separados entre si por um vale no qual se situa a estação do ferry-boat. Não nos foi possível levantar a posição estratigráfica relativa dos dois afloramentos, visto que eles estão separados por uma larga faixa sem exposições de rochas. Além do mais, a região é cortada por numerosos falhamentos que originaram diversas estruturas tipo horst e graben. Fica, portanto, difícil a extrapolação do comportamento faciológico-estrutural através desta faixa sem exposições. Entretanto, observamos que em ambos os afloramentos, de sudeste para noroeste, e, a despeito de todos os falhamentos e escorregamentos existentes, sobe-se na estratigrafia devido ao mergulho regional para nordeste.

Considerando-se que esse mergulho persista de um afloramento para outro e que os falhamentos porventura existentes entre eles possuam rejeitos de pequeno porte, poderíamos concluir que o afloramento situado a noroeste do terminal é estratigraficamente superior ao situado a sudeste.

Duas seçð̃es geológicas esquemáticas são apresentadas com o objetivo de ilustrar o comportamento faciológico-estrutural e o comportamento estratigráfico encontrados.

$\mathrm{Na}$ Fig. $2 A$, podemos observar o afloramento situado a sudeste do terminal. De sul para o norte, começamos com uma fácies de ritmitos argilosos, a qual apresenta da base para o topo um aumento no teor e na espessura de suas areias, passando gradacionalmente para a fácies de ritmitos arenosos. Na parte mediana da primeira fácies; temos camadas de arenitos com geometria lenticular formando a fácies de areias lenticulares. A fácies de ritmitos arenosos continua apresentando espessamento ascendente até a parte mediana de sua espessura, quando então ocorre o auge da alimentação de areias, representado por diversas camadas de areias amalgamadas, com dois níveis conglomeráticos, formando um espesso corpo arenoso (1 m). Daí para cima, o teor de areias e suas espessuras começam a diminuir até que ocorre a passagem gradual para uma fácies superior de ritmitos argilosos. Duas falhas normais, uma de rejeito não muito bem definido, perturbam esta passagem. Daí em frente, a fácies de ritmitos argilosos predomina, apresentando-se sob a forma de um sinclinal suave.

A Fig. $2 B$ representa o afloramento situado a noroeste do terminal. Neste, a complicação estrutural é um pouco maior. De sul para norte ocorre, inicialmente, a fácies de folhelho verde, altamente perturbada por estruturas de escorregamentos, em contato de falha com a fácies de folhelho preto. No bloco alto da falha, esta segunda fácies encontra-se capeatda por um resquício da primeira. Continuando por dentro da fácies de folhelho preto, observa-se um horst no qual encontramos esta mesma fácies, só que agora sobreposta a outra fácies de folhelho verde, sem
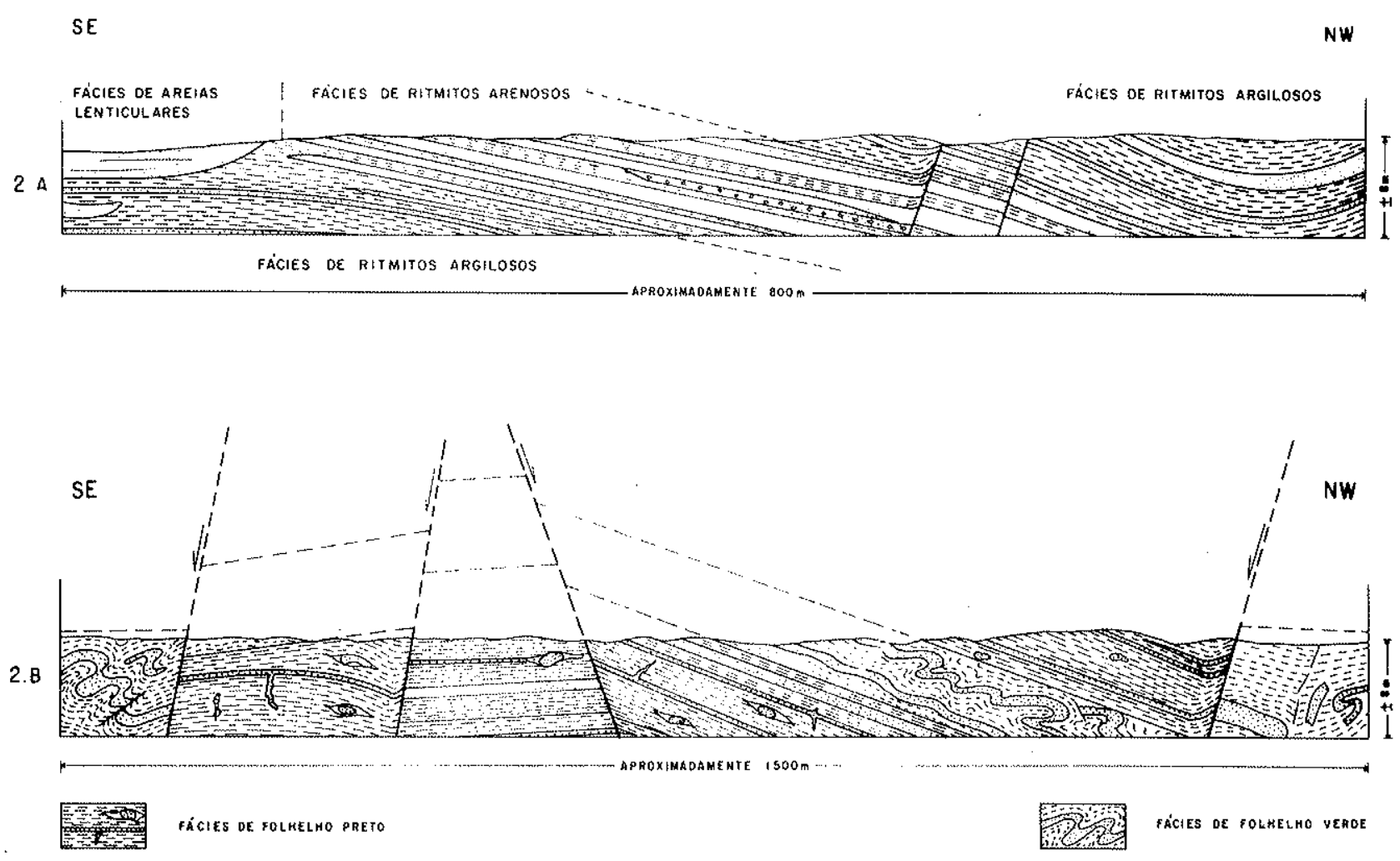

Figura 2 - Seções geológicas esquemáticas dos afloramentos estudados: a sudeste do terminal do ferry-boal $(2 A)$ e a noroeste do terminal $(2 B)$. 
escorregamentos evidentes. Entretanto, o afloramento permite apenas uma visão de alguns decímetros do topo desta segunda fácies de folhelhos verdes. Temos, portanto, duas fácies, uma superior, muito deformada, e outra inferior, mal exposta. Entre as duas ocorre a fácies de folhelhos pretos. Continuando em frente, podemos observar um graben basculado para norte, onde a situação descrita anteriormente se repete. Neste bloco, podemos observar bem o contato entre o topo dos folhelhos pretos a a base dos verdes, com aspecto gradacional. Uma nova fácies de folhelhos pretos aparece sobreposta à fácies de folhelhos verdes mais superior. Nova falha normal faz esta última fácies reaparecer, apresentando o maior grau de deformação observável no afloramento, com arenitos totalmente quebrados, em pedaços soltos em meio aos folhelhos, dobrados e/ou revirados.

\section{c) MEDIÇÃO DE PALEOCORRENTES}

Diversas medidas de paleocorrentes foram efetuadas com o intuito de se saber a procedência das correntes de turbidez responsáveis pelo transporte e pela deposição de grande parte dos sedimentos estudados. Diversas estruturas sedimentares, preservadas nos corpos de arenitos das diversas fácies, foram medidas com esse objetivo. As estruturas utilizadas foram: estratificação cruzada, marcas onduladas e associações de marcas de sola (marcas de estrias com flute marks e/ou prod marks; cristais e valas longitudinais com flutes; e marcas de chevron com flutes). Os resultados obtidos foram plotados em um diagrama de freqüencia (Fig. 3) e as direçőes preferenciais resultantes foram plotadas no mapa de localização (Fig. 1) para se dar uma idéia geográfica da proveniência dessas correntes.

Na Fig. 3, observa-se a existência de três sentidos preferenciais, situados dentro da faixa $\mathrm{S} 35^{\circ} \mathrm{E}-\mathrm{S} 35^{\circ} \mathrm{W}$,

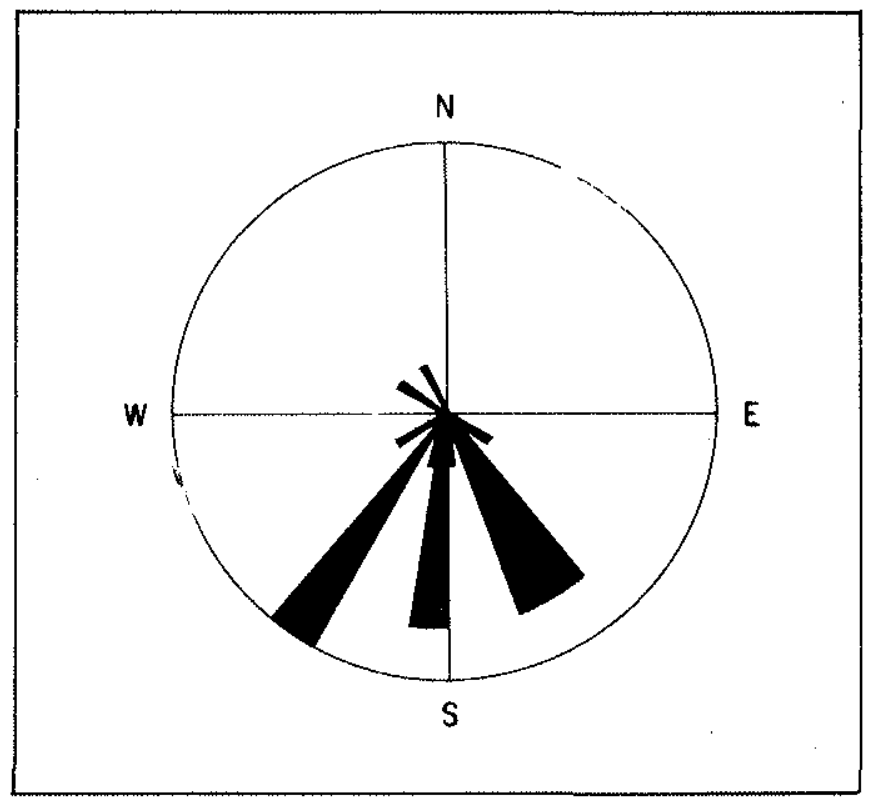

Figura 3 - Diagrama de frequência das direções de paleocorrentes ( 23 medidas) indicando claramente que as correntes vieram de norte para sul. $\mathrm{O}$ sentido principal é $\mathrm{S} 30^{\circ} \mathrm{E}$, nas vizinhanças da qual caíram $40 \%$ das medidas efetuadas. Seguem-selhe S5 $5^{\circ} \mathrm{W}(20 \%)$ e S35 $\mathrm{W}(15 \%)$. Ressalte-se o fato de que todas essas medidas pertencem a arenitos das fácies de ritmitos (arenosos e argilosos) e de areias lenticulares. Não foram efetuadas medidas nas fácies de folhelho verde devido aos fenômenós de escorregamento que deslocaram completamente as camadas de suas posiçðes originais. Muito interessante é o fato de que duas medidas anômalas (correntes para noroeste) pertencem aos arenitos escuros da fácies de folhelhos pretos. Aliando-se este fato à diferença textural nítida entre esta fácies e as demais, somos levados a pensar que a fácies de folhelho preto (ao menos seus arenitos) representa sedimentos de área-fonte diferente, situada a sudeste da área (falha do Salvador?).

\section{INTERPRETAÇÃO AMBIENTAL}

Apresenta-se neste capítulo as interpretaçðes em termos de sistemas e ambientes deposicionais para as diversas fácies estudadas. Concomitantemente, tenta-se o encaixe delas na coluna litoestratigráfica da bacia.

Fácies de folhelhos pretos Os folhelhos pretos betuminosos representam uma sedimentação de fundo de bacia, provavelmente lacustre, em águas não muito profundas (devido à presença de carvão e vegetais fósseis) e em ambiente redutor. Por diversas vezes, variações nas condições ambientais levaram à deposição de micritas, as quais foram posteriormente dolomitizadas. Ocasionalmente, a quietude do meio era perturbada pela incursão de correntes de turbidez, provenientes da falha do Salvador, e que provocaram a deposição de arenitos escuros. Inúmeros pulsos distais dessas correntes estão impressos nos folhelhos em forma de camadas milimétricas mais claras. A alta fluidização desses sedimentos levou à formação de diversos diques de areia. Frisa-se o fato de ser a área-fonte dessas correntes inteiramente diferente da área-fonte das correntes das demais fácies. A falha do Salvador foi apontada como sendo tal devido, principalmente, a dois fatos: $a$ ) as paleocorrentes medidas nos arenitos eram provenientes de sudeste e $b$ ) a composição mineralógica deles é fortemente influenciada pela mineralogia dos granulitos ocorrentes nas imediações da falha (quantidades abundantes de fragmentos de metamórfica rica em clorita, quartzo com extinção ondulante forte e quartzo com inclusões de rutilo).

Baseando-se em nossas descriçð̃es e nas descriçð̃es litoestratigráficas da Bahia do Recôncavo, conclui-se ser esta fácíes representativa dos folhelhos da Formação Candeias. Os arenitos escuros pertencem, provavelmente, ao Membro Morro do Barro da Formação Salvador, que corresponde às partes distais dos conglomerados sintectônicos que ocorrem ao longo da borda leste da bacia. Acredita-se ser esta fácies predominante na época da deposição, tendo sua quietude deposicional perturbada diversas vezes pela atuação de outros processos sedimentares mais energéticos (correntes de turbidez, escorregamentos, etc.). 
Fácies de ritmitos arenosos Como já foi visto anteriormente, os processos atuantes no transporte e na deposição desses sedimentos foram correntes de turbidez. Esta fácies representa, portanto, a implantaçăo de uma fase energética de correntes de turbidez de caráter proximal. Tal caráter é evidenciado pela alta razão areia/folhelho e a grande quantidade de arenitos com sequeencia $T_{b}-e$. Os folhelhos cinzentos representam a parte fina trazida pelas correntes de turbidez. Os períodos de quietude foram raros, tendo em vista as pequenas quantidades e espessuras das camadas de folhelhos pretos serem representativas da sedimentação pelítica normal no fundo da bacia.

Diagnosticou-se um lobo turbidítico, apesar de não ter sido possível o encaixe do modelo observado em nenhum dos modelos de deposição turbidítica conhecidos na bibliografia (de Walker, de Mutti, etc.). Tal impossibilidade pode ser explicada pelo fato de os modelos clássicos lidarem geralmente com grandes leques submarinos, em águas marinhas profundas e alimentados a partir de um canhão. Em nosso caso, estamos em um ambiente lacustre, de águas não muito profundas e, acreditamos, desprovidos de canhões alimentadores (não há evidências na bibliografia geológica regional). Partiu-se, então, para a elaboração de um modelo próprio.

Primeiramente, tentou-se localizar e identificar a área-fonte. Conforme a análise efetuada no subitem "Estratigrafia", as paleocorrentes indicam áreas-fonte ao norte da região. De acordo com os dados bibliográficos sobre a geologia regional, sabe-se que, oriundos do norte, lobos deltaicos do Grupo Ilhas progradavam para o interior do lago existente na época (Formação Candeias). Acredita-se que esses deltas tenham sido os fornecedores dos materiais carregados pelas correntes de turbidez. De acordo com o que temos enfatizado, a composiçăo dos arenitos desta fácies (K-feldspatos, rochas carbonáticas oolíticas, abundante quartzo normal) é completamente diferente dos arenitos da fácies anterior. Tal fato se deve, em grande parte, às áreas-fonte diferentes. A ação de abalos (provavelmente de caráter sísmico) sobre as áreas das frentes deltaicas originariam as correntes de turbidez que se dirigiriam para as partes profundas do lago. A presença de fragmentos de carvăo nesta fácies corrobora a hipótese de área-fonte deltaica para esses sedimentos.

Portanto, o modelo proposto é o de lobos turbidíticos depositados no sopé de taludes deltaicos. Fenómenos sísmicos abalariam as areias da frente deltaica, as quais, sob açấo de correntes de turbidez, seriam carregadas para o fundo da bacia, depositandomse em torno de lobos deltaicos. $\mathrm{O}$ abandono desses lobos pela migração dos canais distributários reflete-se nos turbiditos pela diminuição ascendente no teor e na espessura das areias. Entretanto, esses espessamentos e afinamentos ascendentes podem também ser explicados pela mudan. ça no material suprido pelos distributários devido a aumentos e diminuiçōes na atividade tectónica, respectivamente.

Fácies de ritmitos argilosos De acordo com o modelo exposto, para as fácies anterior, a fácies de ritmitos argilosos inferior representaria a parte distal de um lobo deltaico em processo gradual de implantação. A fácies de ritmitos arenosos sobreposta representa o auge da implantação do lobo causada, talvez, por uma maior atividade tectônica (maior intensidade das correntes de turbidez). Conforme os canais distributários vão migrando e abandonando o lobo deltaico e/ou a atividade tectônica diminui, a frequêencia das correntes de turbidez começa a diminuir gradualmente até surgir de novo a fácies de ritmitos argilosos superior.

Fácies de folhelhos verdes Grandes escorregamentos são geralmente associados à fácies de talude. A intercalação desta fácies com outra representativa de fundo de bacia indica que os folhelhos verdes e os arenitos, altamente perturbados representam materiais lançados para dentro da bacia pelos fenômenos de escorregamento ao longo de um talude subaquoso. Tal talude poderia ser $a$ ) o gradiente da frente deltaica ou $b$ ) um talude resultante de basculamento tectônico da bacia. A segunda hipótese parece ser a mais provável em vista da conhecida atividade tectônica da bacia. No caso da primeira hipótese, os fólhelhos verdes representam argilas intercaladas com as areias da frente deltaica (Grupo Ilhàs). No caso da segunda hipótese, os folhelhos verdes seriam os folhelhos Candeias em uma fácies não redutora intercalada com turbiditos de talude.

Devido à semelhança litológica-textural desta fácies com a de ritmitos, acreditamos que a fácies de folhelhos verdes represente o escorregamento de uma fácies semelhante aos dos ritmitos, ao longo de um talude formado pelo basculamento (local?) da bacia para sudoeste. Parte dos sedimentos estava ainda inconsolidada em vista da ocorrência de arenitos sem estrutura alguma (perdidas durante a movimentação) e com seixos de folhelho verde (adquiridos durante o escorregamento). Entretanto, tais arenitos poderiam representar sedimentos de canal depositados sob o regime de fluxo de grãos. Outra parte dos sedimentos já se encontrava consolidada em vista da ocorrência de camadas de arenito fragmentadas, com os fragmentos preservando as estruturas originais (geralmente sequiências de Bouma).

Fácies de arenitos lenticulares A presença de um corpo de arenito relativamente espesso e de geometria lenticular, composto pelo amalgamamento de várias corridas de turbiditos, em meio à fácies de ritmitos arfilosos inferior, sugere a ocorrência de correntes de turbidez confinadas em uma região restrita, ou seja, em um canal. Teríamos, portanto, um canal de direção nordeste-sudoeste preenchido por correntes de turbidez pro. venientes de nordeste. Seria uma fácies acanalada do lobo turbiditico em estudo.

CONCLUSÓES Ả época da deposição dos sedimentos estudados, existia na Bacia do Recôncavo um grande lago de águas moderadamente fundas. A deposição normal desse lago, em suas partes mais profundas, era de lamas ricas em matéria orgânica, por vezes micríticas, em um ambiente redutor propicio à preservaçåo do conteúdo orgânico (Formação Candeias). Este lago era limitado em sua parte oriental pela falha do Salvador, a qual, em franca atividade tectónica, provocava a depo- 
sição de cunhas de clásticos nas bordas da bacia (Formação Salvador) e originava correntes de turbidez que, ocasionalmente, chegavam até as partes mais profundas da bacia, depositando delgadas areias em meio às lamas escuras (fácies folhelhos pretos) (Fig. 4).

Ao norte, deltas do Grupo Ilhas progradavam para o interior do lago e, juntamente com a atividade tectônica da bacia, perturbavam a calma sedimentação da Formação Candeias de dois modos: $a$ ) pelo lançamento de correntes de turbidez originadas nas frentes deltaicas e que depositavam lobos turbidíticos no interior da bacia (fácies de ritmitos arenosos e de arenitos lenticulares), e pelos escorregamentos, ou da frente deltaica ou de turbiditos já depositados (fácies de folhelhos verdes).

Agradecimento Este trabalho foi realizado sob a coordenação e orientação do Prof. Rodi Ávila Medeiros, do Setor de Ensino da Petrobrás na Bahia. A ele se dirigem nossos agradecimentos, extensivos também à Sra. Ivonildes Fonseca, pela datilografia do trabalho, e ao Sr. José Hélio de Carvalho, pela confecção dos desenhos. Agradecemos também ao Prof. Francisco Celso Ponte pelas sugestðes e críticas apresentadas durante a revisão deste trabalho.

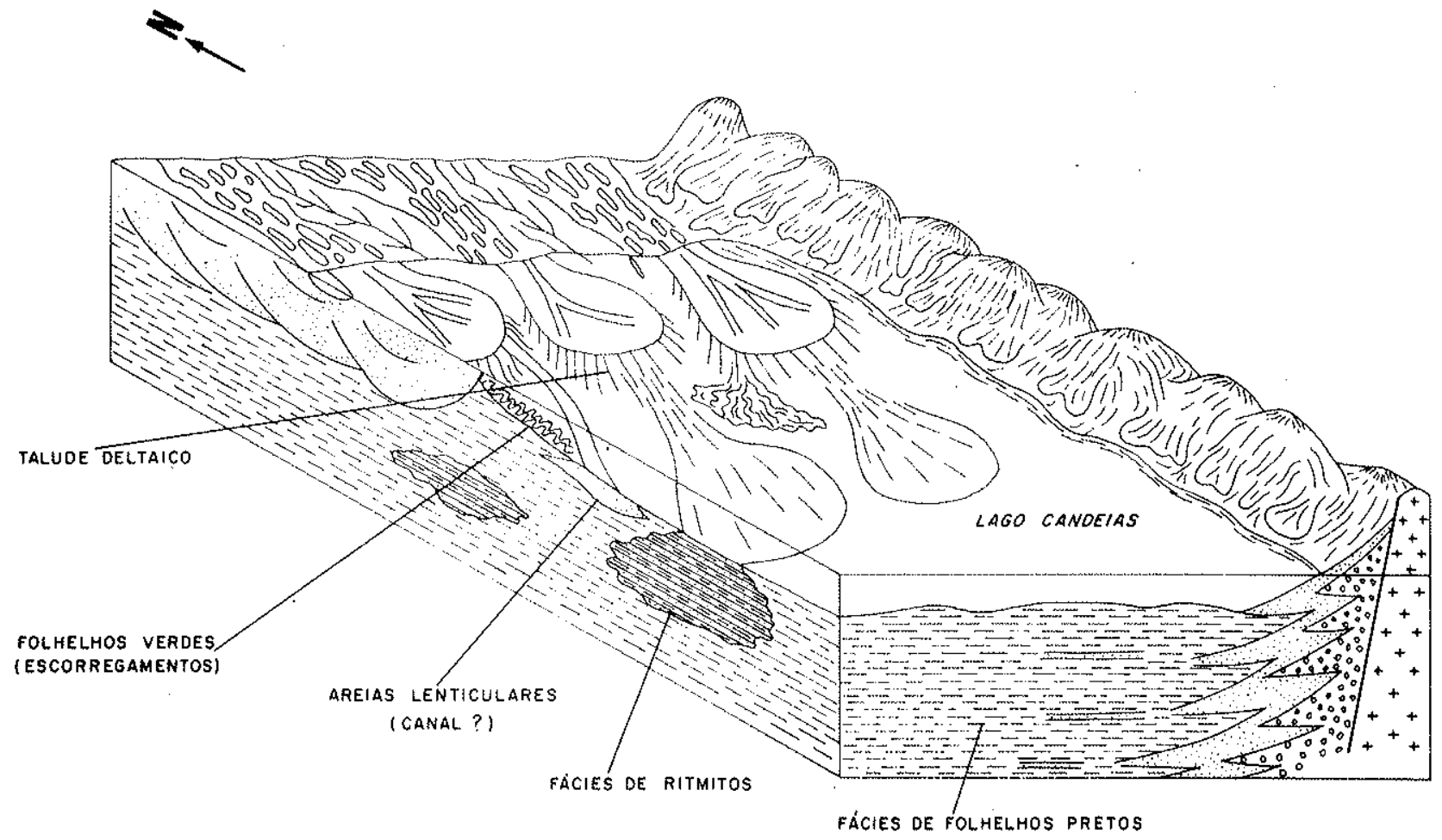

Figura 4 - Bloco-diagrama mostrando as relações entre as diversas fácies estudadas à época da deposiçăo.

\section{BIBLIOGRAFIA}

APOLUCENO NETO, A. F, e ZALÁN, P. V. - 1979 - Reconhecimento de Turbiditos através de Perfis Elétricos. Exemplos dás Bacias Costeiras do Nordeste do Brasil. Anais do IX Simpósio de Geologia do Nordeste (no prelo), Natal.

BOUMA, A. H. - 1962 _... "Sedimentology of Some Flyscls Deposits". Amsterdam, Elsevier Publ. Co., 169 pp.

FOLK, R. L. ANDREWS, P. B. e LEWIS, D. W. -1970 - Detrital Sedimentary Rock Classification and Nomenclature for use in New Zealand. N. $Z$. Jl. Geol. Geophys. 13:937-968.

GHIGNONE J. I. - 1972 - A Evolução Estrutural do Recôncavo durante o Tempo Candeias. Revista Brasileira de Geociéncias 2, pp. 35-50.

GHIGNONE, J. 1. - 1978 - Os Turbiditos de Bom Despacho, Bahia. Anais do XXX Congresso Brasileiro de Geologia, Recife, vol, 8, pp. 793.798.

MIDDLETON, G. V. E HAMPTON, M. A. - 1976 - "Subaqueous sediment transport and deposition by sediment gravity flows". In D. J. Stanlcy and D. J. P. Swift (eds), "Marine Sediment Transport and Enviuronmental Management". New York, Wiley Intersci., pp. 197-238.
MEDEIROS, R. A., SCHALLER, H. e FRIEDMAN, G. M. - 1971 - Fácies Sedimentares. Bol. Ciéncia - Técnica - Petróleo, CENPES Rio de Janeiro.,

NETTO, A. S. T. - 1978 - A Implantação da Fase Rift na Bacia do Recôncavo. Anais do XXX Congresso Brasileiro de Geologia, Recife, vol, 1, pp. 506-517.

VIANA, C. F. e outros - 1971 - Revisão Estratigráfica da Bacia Recôncavo/Tucano. Boletim Técnico da Petrobrás, 14, (3/4): 157-192.

WALKER, R. G. - 1978 - Deep-Water Sandstone Facies and Ancient Submarine Fans: Models for Exploration for Stratigraphic Traps. AAPG Bull., yol. $62 / 6$, pp. $932-966$. 